\title{
Remote Laboratories in Engineering Education - an Overview of Implementation and Feasability
}

\author{
Dag A. H. Samuelsen \\ Kongsberg Institute for Engineering University College of Southeast Norway 3611 Kongsberg, Norway \\ Email: dag.samuelsen@hbv.no \\ Olaf H. Graven \\ Kongsberg Institute for Engineering University College of Southeast Norway 3611 Kongsberg, Norway \\ Email: olaf.hallan.graven@hbv.no
}

\begin{abstract}
Remote laboratories has become a mature technology in many aspects, and is used extensively at universities around the world. This paper describes remote laboratories in general, and shows an example of how remote laboratories can be utilised as an integral part of engineering education. Specifically, the paper demonstrates a low-cost, simple, yet advanced remote laboratory setup for use in an analogue electronics module. These remote laboratories can easily be implemented into an engineering curriculum, without an overwhelming effort from the staff, and for the benefit for the students, in terms of pedagogy.

Keywords-Remote Laboratories, Engineering education, Pedagogy.
\end{abstract}

Digital Object Identifier (DOI):

http://dx.doi.org/10.18687/LACCEI2016.1.1.050

ISBN: 978-0-9822896-9-3

ISSN: 2414-6390

$14^{\text {th }}$ LACCEI International Multi-Conference for Engineering, Education, and Technology: "Engineering Innovations for Global Sustainability", 20-22 July 2016, San José, Costa Rica. 


\section{Remote Laboratories in Engineering Education - an Overview of Implementation and Feasability}

\author{
Dag A. H. Samuelsen \\ Kongsberg Institute for Engineering \\ University College of Southeast Norway \\ 3611 Kongsberg, Norway \\ Email: dag.samuelsen@hbv.no
}

\author{
Olaf H. Graven \\ Kongsberg Institute for Engineering \\ University College of Southeast Norway \\ 3611 Kongsberg, Norway \\ Email: olaf.hallan.graven@hbv.no
}

\begin{abstract}
Remote laboratories has become a mature technology in many aspects, and is used extensively at universities around the world. This paper describes remote laboratories in general, and shows an example of how remote laboratories can be utilised as an integral part of engineering education. Specifically, the paper demonstrates a low-cost, simple, yet advanced remote laboratory setup for use in an analogue electronics module. These remote laboratories can easily be implemented into an engineering curriculum, without an overwhelming effort from the staff, and for the benefit for the students, in terms of pedagogy.
\end{abstract}

Index Terms-Remote Laboratories, Engineering education, Pedagogy.

\section{INTRODUCTION}

The learning objectives of engineering education consists of a diversity of skills, knowledge and competence, which the apt engineer must master in their profession. Maintaining a laboratory requires a number of resources, where the main factors are facilities like rooms and equipment, but also staff. Universities with many engineering students will consume many resources for such laboratory activities. There will often be a desire from the university management to reduce the cost of running the university in general, and laboratory activities might be a victim when the management from time to time needs to reduce costs. However, from a quality perspective, the students must receive an adequate amount of practice training through laboratory work, in order to have engineers that are competitive on the labour market, which in turn maintains the reputation of the university among prospective students.

Letting the students do laboratory work will, in itself not be enough to fulfil the learning objectives of the engineering education curriculum. A laboratory exercise will typically give the student training in a number of different skill and competence areas within the complete range of learning objectives to be met. It is also often designed to aid the understating of knowledge. An example can be found in an analogue electronics module of an electrical engineering education. In this module, the students should be able to:

- Read and interpret schematic diagrams (required knowledge and skill)

- Wire up a circuit on a breadboard (required skill)

- Troubleshooting circuits in general (required knowledge and skill)
- Identify working and broken components and wires (required knowledge and skill)

- Using and connecting power supplies, voltmeters, ampere meters, oscilloscopes, etc. (required mainly skill and general competence)

Equally important is the establishment of an intuitive understanding of how electric circuits behave, by creating a link between what is happening on the breadboard and the theory the students learn in class and from the textbook. The authors of [1] experienced that, for the more complex circuits like the one presented in figure 1, the students ended up receiving too much training in troubleshooting, to the degree that they spent all their cognitive resources on that, rather than the other training elements in the lab. Most importantly, many of them failed to create the link mentioned above, which is considered crucial for gaining an intuitive understanding for how analogue circuits of this type works and the theory behind analogue circuits in general. The problem was identified to be the lack of ability to adapt the amount of training each individual student received in each of the learning objectives of the laboratory exercise, to the specific need of each student.

A suggested solution to both the cost issue and the adaptation issue was the creation of a remote laboratory. Laboratories in general are classified by [2] into four types: "hands-on-lab", "remote lab", "local simulation", and "virtual lab". A simple definition of a remote laboratory is a physical laboratory that can be remote controlled by the user, as opposed to the virtual lab, which is a simulation only. At the authors university, remote laboratories are used for adjusting the level of training each student receive in the different learning objectives, by reducing or removing the elements for which the individual student do not need extra training. There are some side-effects of this arrangement, as described in the next subsections.

\section{A. Availability 24/7, "everywhere"}

The remote laboratory is available for the students at the time and place of their choice, as long as there is an internet connection available. Figure 2 shows an example of a user interface for a remote laboratory when accessed through a smart phone. This user interface utilizes HTML5 and JavaScript to make the system available on many platforms, ranging from desktop and laptop PCs, to tablets and smart phones. This

Digital Object Identifier (DOI): http://dx.doi.org/10.18687/LACCEI2016.1.1.050 ISBN: 978-0-9822896-9-3

ISSN: $2414-6390$

14 ${ }^{\text {th }}$ LACCEI International Multi-Conference for Engineering, Education, and Technology: "Engineering Innovations for Global Sustainability”, 20-22 July 2016, San José, Costa Rica. 


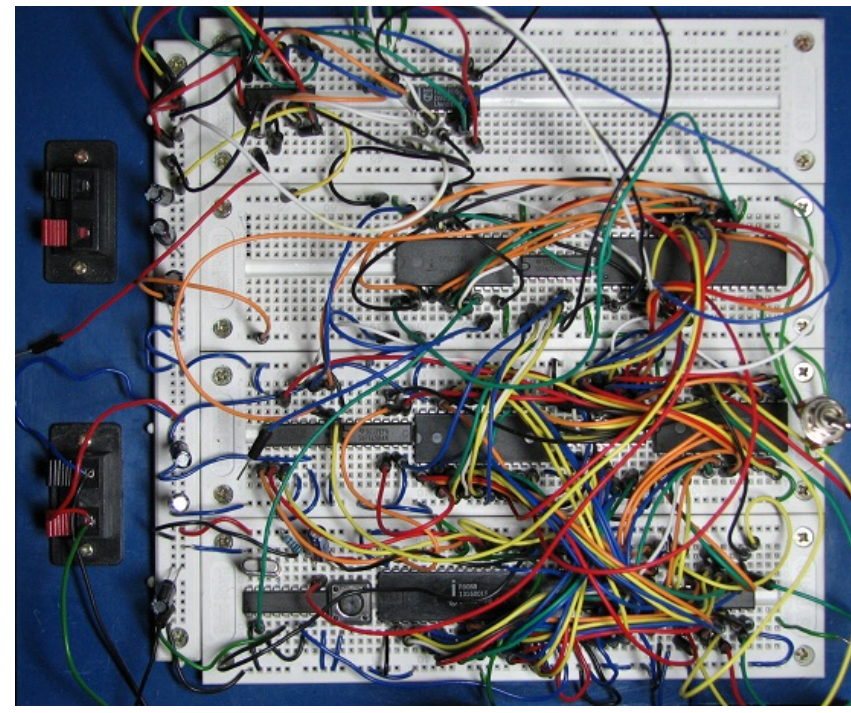

Fig. 1. Complex circuit setup on a breadboard.

system is previously published in [3], and demonstrates that a fully functional remote laboratory can be implemented on simple, low cost hardware such as Arduino, with a virtual machine as web server. This particular user interface is made to have a very low entry level for the user, and figure 3 shows that different component values can be selected through a pulldown menu. It also demonstrates that a remote laboratory can be accessed and used by students from both mobile devices as well as PCs.

The analysis of the sampled data is made equally simple, as shown in figure 4 . The user interface allows the user to zoom in and out, select which data series to display, and the possibility to see the momentary values at each time step.

The use of remote laboratories is beneficial for students who has work besides their studies, are ill, or are otherwise hindered from participating in the laboratory at the times set up by the staff. The students can also repeat the laboratory exercises as many times as they desire without any extra assistance required from staff, in order to gain a better understanding and further knowledge. In [4], some of the students reported that they used the laboratory extensively (actually going as far as what can only be described as playing with the circuit), and thereby developed a deeper understanding for how the circuit actually worked, and how different choices of component values influenced the behaviour of the circuit.

The entry level to investigate the behaviour of the circuit, and the creation of a link between the theory the students learn in class, and what is happening in the circuit at hand, should be as low as possible. The difference in entry level of the user interface shown in figures 2,3 and 4 , and the "user interface" presented in figure 1 should be clear to the reader.

\section{B. Sharing}

It is a fact that a remote laboratory easily can be shared between universities, and the number of remote laboratories available for the students can be much higher than the number

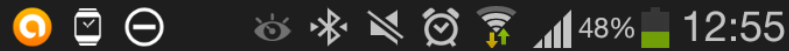
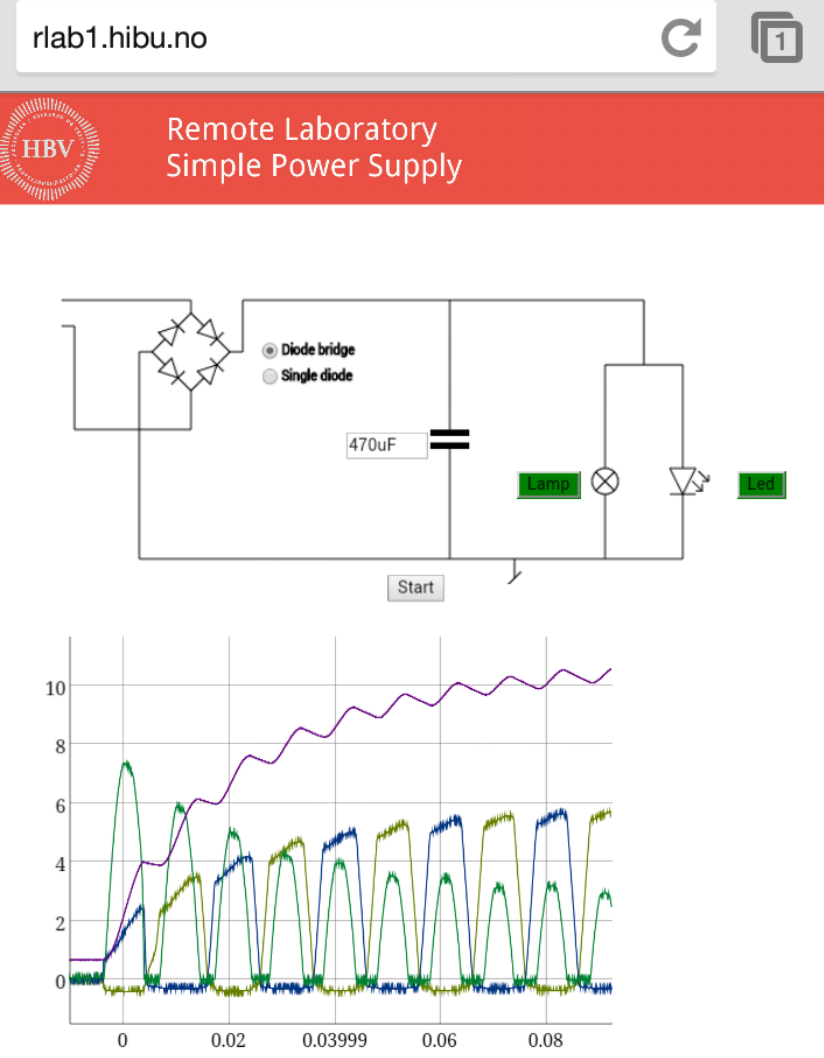

Show Series:

$\checkmark$ AC Phase A $\downarrow$ AC Phase B $\downarrow$ Current $\downarrow$ DC Voltage

Fig. 2. User interface to the remote laboratory when accessed through a smart phone.

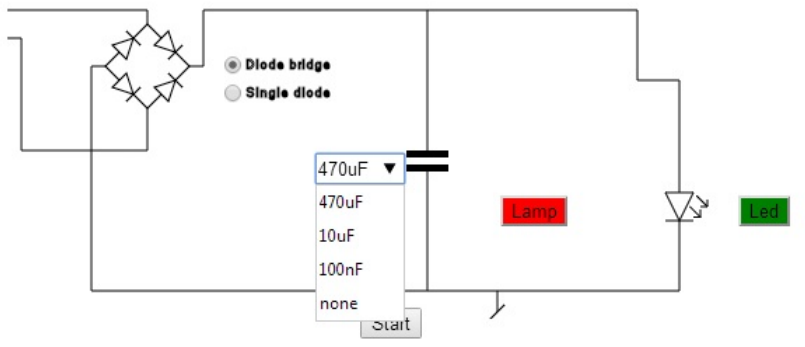

Fig. 3. User interface used for selecting between different components. 


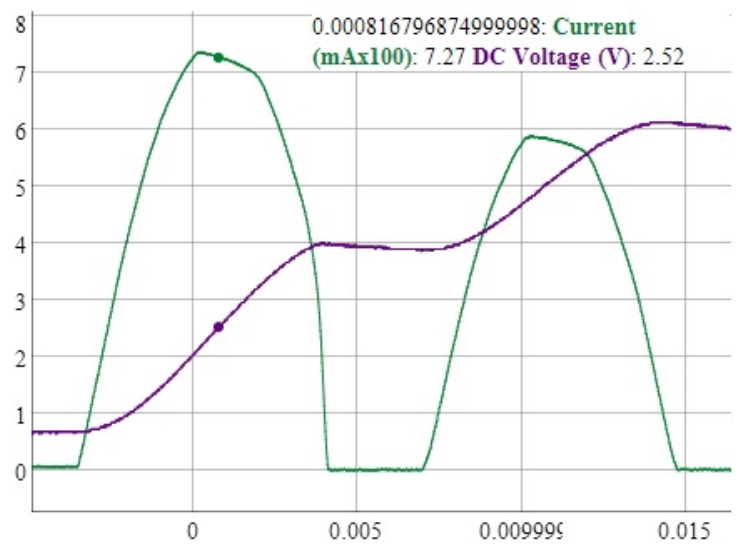

Show Series:

$\square$ AC Phase A $\square$ AC Phase B $\square$ Current $\square$ DC Voltage

Fig. 4. User interface when zooming in on sampled values.

present at their own university. There are projects and consortiums created specifically for this purpose. The iLab project [5] is a system which consists of lab clients, a service broker and lab servers, as well as a lab resource scheduling service which allows for batch run of pre-configured experiments and for experiments that require interactive control from the user during the experiment.

Another example is The Global Online Laboratory Consortium (GOLC) (http://www.online-lab.org/) which has been created to facilitate the creation and distribution of shared remote laboratories. The organisation carries the statement "The mission of the consortium is the creation of sharable, online experimental environments which increase the educational and scientific value of learning which may not be accessible, scalable or efficient through traditional methods". One of the outcomes of the latter is the Labshare (http://www.labshare.edu.au/) which have developed a resource kit reported on in [6] "to facilitate the engagement of academics".

\section{The challenge of supervising in remote laboratories}

A significant challenge of using remote laboratories is the lack of staff present to aid and guide the students throughout the exercise. In a normal laboratory setting, the staff will typically be present in the room with the students, and offer help whenever they discover that the student is doing something wrong, or simply answer questions that the students have there and then, to facilitate the understanding of theory and aid if a specific skill of a student is lacking.

It is possible to use e-mail or other asynchronous or synchronous messaging system between the students and a supervisor, but due to the fact that some students prefer to work at odd times of the day or at night, often the supervisor will not be present when the student have a question or is clearly struggling. There has been a few simple experiments with automated systems for support but much effort is needed into this field, and the problem still remains.

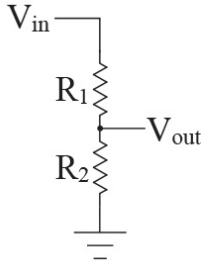

Fig. 5. Resistor voltage divider.

\section{DESIGN AND IMPLEMENTATION OF REMOTE LABORATORIES}

\section{A. Experiment hardware back-end}

A virtual laboratory is a simulation, whereas a remote laboratory runs on real hardware. The latter therefore requires some sort of controlled hardware for running the experiment on. The hardware will be similar to what is used in a normal hands-on laboratory exercise, with one major difference. The experiment must be remotely reconfigurable, in order for the user to be able to alter the parameters of the experiment.

An example of this can be found in the simple voltage divider circuit, which consists of two resistor in series, as shown in figure 5. The output voltage $V_{\text {out }}$ is a function of the combination of the two resistor values and the input voltage $V_{i n}$. To make this remotely configurable, an analogue multiplexer or analog switch is used for connecting and disconnecting a range of real, physical resistors in a circuit.

An example of such a circuit is shown in figure 6, where $\mathrm{U} 20$ and $\mathrm{U} 21$ is the analogue multiplexers, and U5 is a register used for storing the configuration during the experiment. One of the resistors R1 through R16 is selected for the first leg of the voltage divider, while one of the resistors R17 through R32 is selected for the second leg. In order to simplify the development of the remote laboratory experiment hardware, this voltage divider circuit is placed on a separate module, as shown in figure 7 to the left. The middle board allows the user to select one of eight different transistors, while the rightmost allows for selecting different capacitor values.

These boards can then be mounted into a main experiment board as shown in figure 8 . This system represents a readymade solution for experiment setup as published previously in [7]. This system significantly reduces the effort and resources needed to implement the experiment hardware for a remote laboratory in modules such as electric circuits and analogue electronics.

\section{B. Remote access to the laboratory}

An important part of a remote laboratory is the ability to control and configure the experiment remotely. In early remote laboratory systems, a popular choice was the NI/LabVIEW hardware/software solutions. Examples can be found in [8] and in [9] where the control and software frontend is made from NI/LabVIEW. However, as reported in [4], the use of "Remote Panels" in LabVIEW for internet access to the remote laboratory, sets a significant limit on which client platforms 

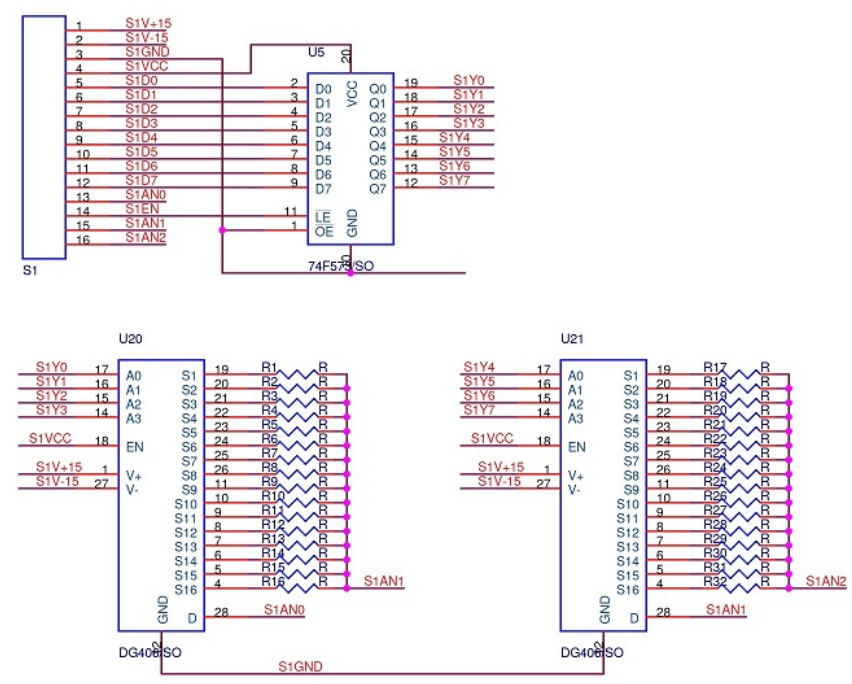

Fig. 6. Electronic reconfigurable resistor voltage divider.

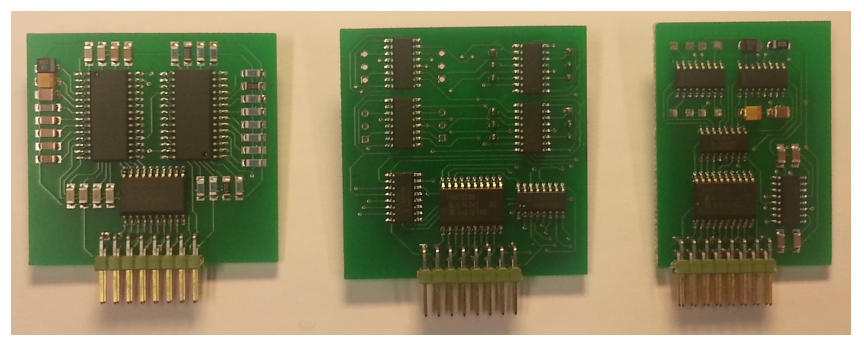

Fig. 7. Electronic reconfigurable component boards.

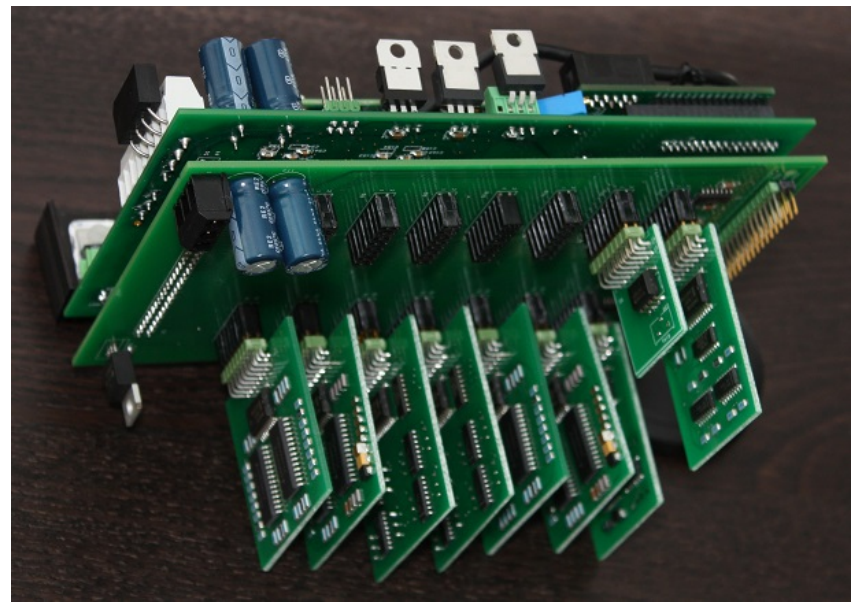

Fig. 8. Main experiment component board with component boards mounted. that can possibly be used to connect to the remote laboratory. The students also reported that they were very disappointed with the trouble caused by the software. Others focus on mimicking the real world physical instruments, such as [11]. In developing the user interface, the developer should be clear on what purpose the experiment serves. If the learning objective the remote laboratory should give training in, is using the instruments, then mimicking real world instruments is a good idea. If the purpose of the remote laboratory is to create a link between the theory the students learn from the textbook and what happens in a real world circuit, then a low entry level of the user interface should come first. This is further discussed in [12]

In recent years, the ability to access remote laboratories on mobile devices have gained interest. The use of e-portfolios in combination with access to remote laboratories is investigated in [13], and apps used for accessing remote laboratories is demonstrated in [14]. The authors of this paper, however, focus on platform independency. In [10] it is demonstrated how to build a remote laboratory front-end using HTML5 and JavaScript, as shown in figure 9 thereby allowing for a much broader range of platforms to connect to the remote laboratory, as previously described in the introduction of this paper. In the same paper, it is reported from a survey conducted among the students regarding their experiences with using the remote laboratory front-end. None of the respondents in [10] are in any way negative towards the front-end, and the vast majority is very positive when asked about "ease of access" to the remote laboratory. This in contrast to the survey reported in [4], where the students were clearly negative towards the usability of the front-end produced using "remote panels" in NI/LabVIEW.

\section{Data acquisition}

In order to analyze the circuit of the experiment, several measurements is needed. This is precisely the same as with the hands-on laboratory, the only difference being measurement data needs to be digitized and transferred through the internet to the user, and presented in the user interface. The hardware for digitizing the measurement data varies depending on a number of factors, such as frequency of the signal to be measured, amount of data to be sampled, and type of signal.

In [15] a comparison between three different devices: The professional NI USB-6008, the Arduino ATmega1280 and the PIC18F4550. The main conclusion is that for the purpose of remote laboratories, there are no significant arguments for not choosing the low-cost devices, such as the Arduino ATmega1280 and the PIC18F4550. The effort needed to have a fully functional solution is considered to be roughly the same for the three variants. The main problem with these devices are the limited number of simultaneous sampling inputs. For low frequency applications, typically below $100 \mathrm{~Hz}$, this is not a problem as the multiplexed input of the devices allows for several signals to be sampled close enough. For higher frequencies the limited storage capacity, the sampling rate, and the cross talk between input channels on multiplexed devices, 

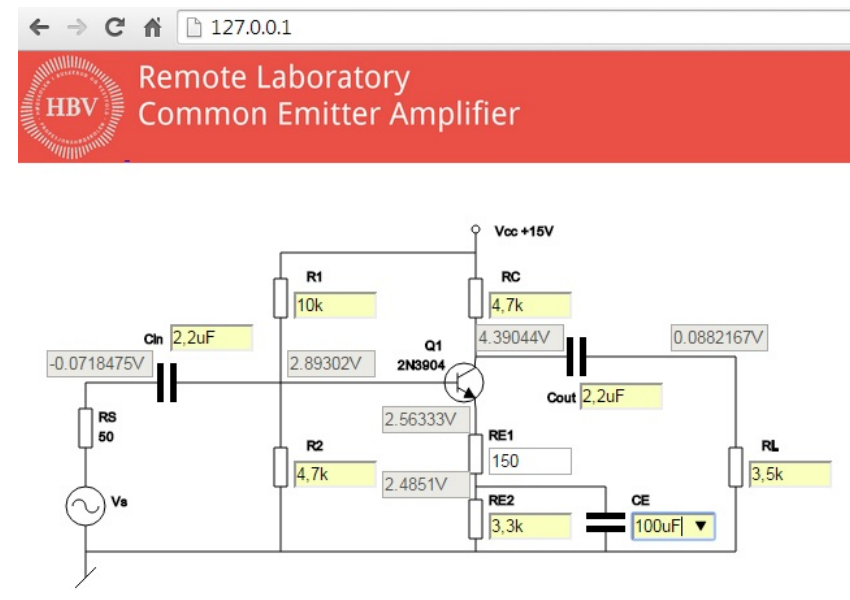

Start

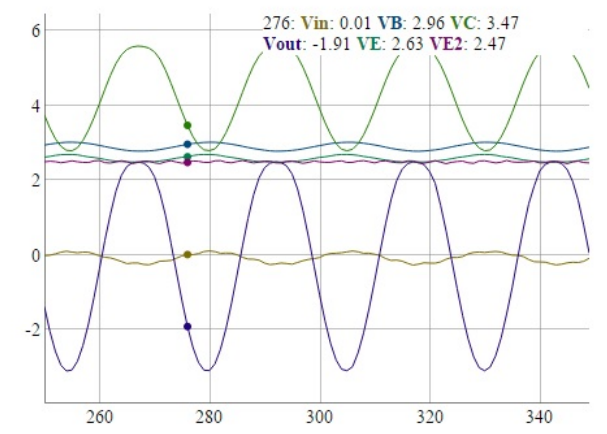

Show Series:

$\downarrow \mathrm{Vin} \downarrow \mathrm{VB} \triangleright \mathrm{VC} \downarrow \mathrm{Vout} \vee \mathrm{VE} \downarrow \mathrm{VE} 2$

Fig. 9. Main experiment component board with component boards mounted.

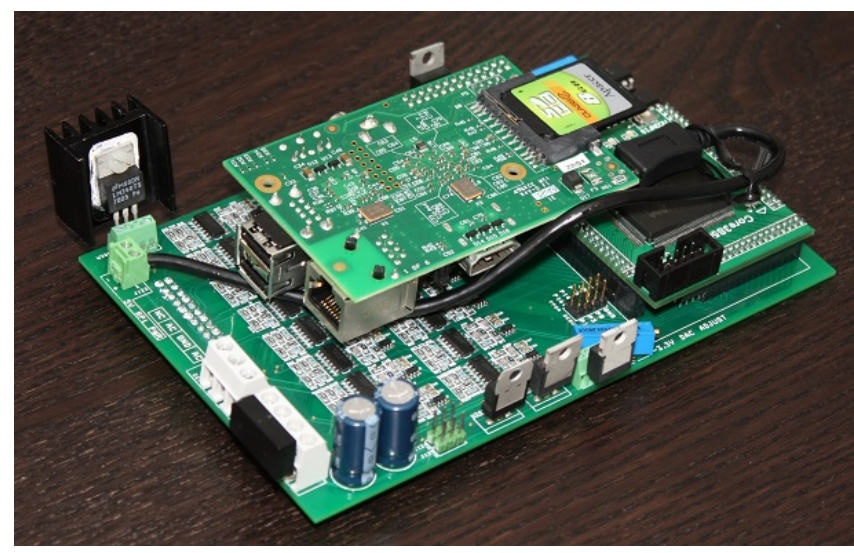

Fig. 10. Multi-channel sampler and signal generator for remote laboratory applications.

all becomes significant problems. Commercial devices exist that overcome this problem, such as the NI PXIe-6358 [17], but a cost of $\$ 6,000 \mathrm{USD}$ effectively eliminate the possibility of having a low-cost solution.

In [16] it is shown a low-cost, multi-channel sampler and signal generator, which offer an adequate level of quality

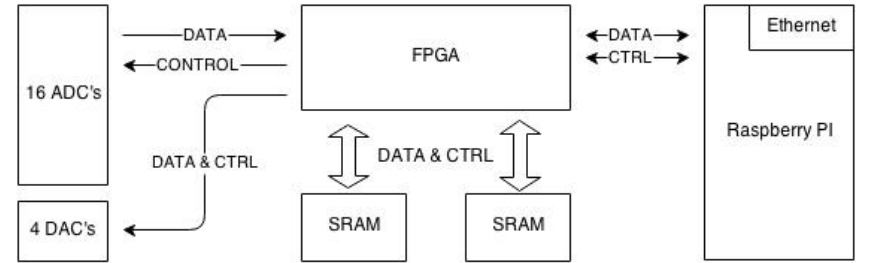

Fig. 11. Overview of the sampler and signal generator.

for the purpose of remote laboratories. Figure 10 shows the sampler which goes on top of the main board for the component boards. In figure 11 an overview of the sampler is given. Here it can be seen the FPGA used for controlling the experiment hardware, the ADCs and the DACs. Also shown is the SRAM for storing measurement data before transfer to a RaspberryPi, which holds the network interface for accessing data. The sampler can simultaneously sample 16 channels of 12 bits each, and generate 4 simultaneous output signals, all at a data rate of maximum $250 \mathrm{kS} / \mathrm{s}$. This sample rate makes it suitable for most electric and analogue electronics experiments.

\section{Assessment OF QUALITY}

The authors' main argument for doing work on remote laboratories is the prospects of improved pedagogical quality of the engineering education. In order to assess whether there are any improvement, several surveys have been conducted among the students and their use of remote laboratories. The paper [4] reports on a survey among students using a remote laboratory for a simple power supply. The aim here was to remove some of the disturbing elements when trying to create the link between theory and practice, as explained in the introduction. Not only did the students report that they felt the lab easier to work with, but a small group of students did something that can be described as playing with the system, in the sense that they used the lab for an extensive amount of time, trying out different scenarios. This type of behaviour will in the authors' opinion, contribute a lot to the creation of the link previously mentioned.

In the same survey, the students did on the other hand express a large degree of dissatisfaction with software system used to give access to the remote laboratory. The remote laboratory that were used by those students, was designed using LabVIEW remote panels. This requires the users to install extra software on their computers, but also requires certain ports to be opened on firewalls both on their computers and in the routers between the user and the experiment server. Both of these requirements turned out to be a source of much frustration in working with the remote laboratory, reducing the perceived quality of the service. Because of this, the remote laboratory interface based on LabVIEW, was converted into a system based on HTML5, as reported on in [18]. The students answered a survey where they rated their experience with the remote laboratory in the context of ease of access, perceived learning outcome, ease of understanding the use of 

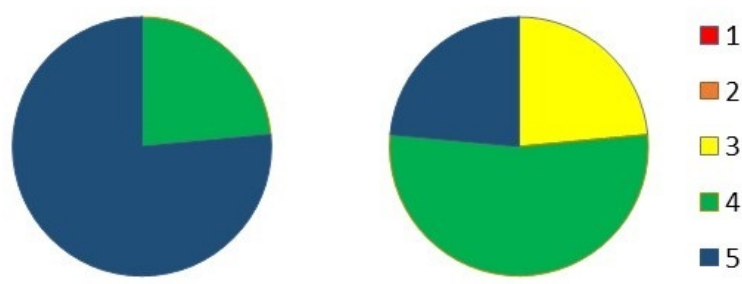

Fig. 12. Student response: Ease of access, and General impression
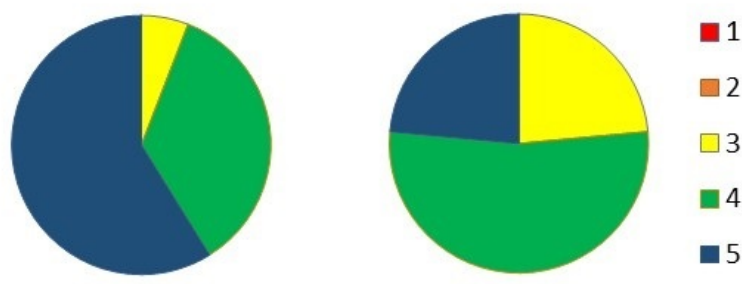

Fig. 13. Student response: Ease of understanding, and Instructive

the interface, and a general impression. The results from a 5point Likert scale survey are shown as pie-charts in figure 12 and 13.

Looking at the charts, a remarkable feature is that none of the respondents used the negative part of the Likert scale, and only a fraction of the respondents were neutral in their experience with their use of the remote laboratory interface. It turned out to be difficult to conduct a survey or use statistical analysis to show any clear correlation between the students' grades and the introduction of the exercise program, as there are too many other factors with unknown impact on their grade, including variance in the student's background and knowledge level. The remote laboratory alone cannot cover all the learning objectives of the exercise program, especially the hands-on part. However, the overall impression is that the students gain a better and more intuitive understanding for how the circuits actually works through the use of the remote laboratory, and that this has a positive effect on how they perform in the hands-on laboratory exercises.

\section{CONCLUSIONS}

In this paper, it is demonstrated that remote laboratories can be implemented with relatively low effort from the staff at the university, and at a low cost, compared to the cost of running a hands-on laboratory. Cost saving and accessibility for students not present on campus has been a frequent argument for the introduction of remote laboratories. However, as the authors of this paper tries to convey partly in this paper and previous publications: There are pedagogical arguments for the introduction of remote laboratories, where the cost saving and accessibility for the student comes as a bonus. The authors have also shown some of the pitfalls which should be avoided when implementing remote laboratories. The main point from the paper is that it is feasible for almost any university with engineering education, regardless of number of students and budget, to implement remote laboratories as an improvement of the curricula, in order to educate better engineers.

\section{REFERENCES}

[1] D. A. H. Samuelsen and O. H. Graven "Remote lab for experiments on a small-signal bipolar-junction transistor amplifier", in Global Engineering Education Conference (EDUCON), 2011 IEEE, pp.721-725, 4-6 April 2011

[2] D. G. Zutin, M. E. Auer, C. Maier, and M. Niederstatter "Lab2go A repository to locate educational online laboratories" in Education Engineering (EDUCON), 2010 IEEE, 2010, pp. 1741-1746.

[3] D. A. H. Samuelsen, J. Bjork and O. H. Graven, "Work in progress: Simple software solution for accessing remote lab on mobile devices" in Teaching, Assessment and Learning (TALE), 2014 International Conference on , vol., no., pp.69-72, 8-10 Dec. 2014

[4] O. Graven and D. A. H. Samuelsen, "Report on engineering students use of a remote power supply laboratory" in S. Barton, J. Hedberg \& K. Suzuki (Eds.), Proceedings of Global Learn 2011 (pp. 1568-1575). Association for the Advancement of Computing in Education (AACE).

[5] J. L. Hardison, K. DeLong, P. H. Bailey, and V. J. Harward, "Deploying interactive remote labs using the iLab Shared Architecture" in Frontiers in Education Conference, 2008. FIE 2008. 38th Annual, 2008, pp. S2A1-S2A-6.

[6] E. Lindsay, S. Murray, and B. D. Stumpers, "A toolkit for remote laboratory design \& development" in Global Online Laboratory Consortium Remote Laboratories Workshop (GOLC), 2011 First, 2011, pp. 1-7.

[7] D. A. H. Samuelsen and O. H. Graven, "Highly configurable low cost remote laboratory with integrated support for learning - Hardware design" in International Journal of Online Engineering (iJOE), 2013, Vol. 9, pp. 31-37.

[8] L. Wu, D. Cartes, C. Shih, "Web-Based Flow Control of a Three-Tank System" in Journal on Systemics, Cybernetics and Informatics (JSCI), Volume 2, Number 1, pp.77-82, 2004.

[9] D. Hercog, B. Gergic, S. Uran, and K. Jezernik, "A DSP-Based Remote Control Laboratory" in IEEE Transactions on Industrial Electronics, vol.54, no.6, pp.3057-3068, Dec. 2007.

[10] D. A. H. Samuelsen, J. Bjork, and O. H. Graven, "Converting a remote laboratory back end from remote panels in LabVIEW to HTML5" in Remote Engineering and Virtual Instrumentation (REV), 2015 12th International Conference on , vol., no., pp.220-222, 25-27 Feb. 2015.

[11] M. Tawfik, E. Sancristobal, S. Martin, R. Gil, G. Diaz, A. Colmenar, et al., "Virtual Instrument Systems in Reality (VISIR) for Remote Wiring and Measurement of Electronic Circuits on Breadboard", IEEE Transactions on Learning Technologies, vol. 6, pp. 60-72, 2013.

[12] J. P. C. de Lima, W. Rochadel, A. M. Silva, J. P. S. Simao, J. B. da Silva, and J. B. M. Alves, "Application of remote experiments in basic education through mobile devices", in Global Engineering Education Conference (EDUCON), 2014 IEEE, 2014, pp. 1093-1096.

[13] D. May, C. Terkowsky, T. Haertel, and C. Pleul, "The laboratory in your hand Making remote laboratories accesible through mobile devices" in Global Engineering Education Conference (EDUCON), 2013 IEEE, 2013, pp. 335-344.

[14] M. Latorre Garcia, G. Carro Fernandez, E. Sancristobal Ruiz, A. Pesquera Martin, and M. Castro Gil, "Rethinking remote laboratories: Widgets and smart devices" in Frontiers in Education Conference, 2013 IEEE, 2013, pp. 782-788.

[15] D. A. H. Samuelsen and O. H. Graven, "Assessment of the quality of low cost data acquisition equipment for remote lab setups" in Remote Engineering and Virtual Instrumentation (REV), 2013 10th International Conference on , vol., no., pp.1-6, 6-8 Feb. 2013.

[16] D. A. H. Samuelsen and O. H. Graven, "Low-cost multi-channel analog sampler and signal generator for remote laboratories" in Remote Engineering and Virtual Instrumentation (REV), 2015 12th International Conference on , vol., no., pp.100-104, 25-27 Feb. 2015

[17] NI PXIe-6358. Available: http://sine.ni.com/nips/cds/view/p/lang/en/nid/209216.

[18] D. A. H. Samuelsen, J. Bjork, and O. H. Graven, "Converting a remote laboratory back end from remote panels in LabVIEW to HTML5" in Remote Engineering and Virtual Instrumentation (REV), 2015 12th International Conference on , vol., no., pp.220-222, 25-27 Feb. 2015. 